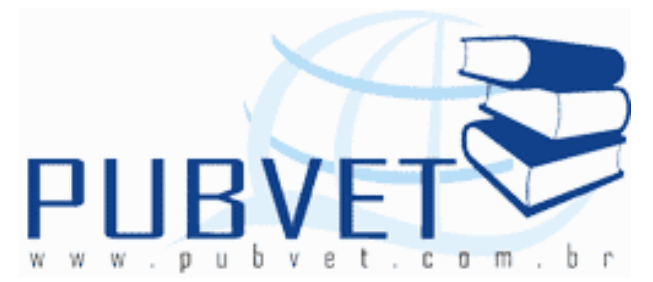

PUBVET, Publicações em Medicina Veterinária e Zootecnia.

\title{
Anatomia da fixação proximal do músculo reto femoral em humanos, Cebus apella e Alouatta guariba
}

\footnotetext{
Lorena Tannús Menezes Amado ${ }^{1}$, Gilmar da Cunha Sousa ${ }^{2}$, Daniela Cristina de Oliveira Silva², Zenon Silva, Roberto Bernardino Júnior², Miguel Antônio Facury Neto², Frederico Balbino Lizardo², Lázaro Antônio dos Santos ${ }^{1}$, Roseâmely Angélica de Carvalho Barros ${ }^{2}$, André Luiz Quagliatto Santos ${ }^{2}$.
}

Laboratório de Anatomia Humana do Instituto de Ciências Biomédicas ICBIM/UFU, email: gilmar@ufu.br 1. Bióloga, Universidade Federal de Uberlândia. 2. Docentes.

\section{Resumo}

Realizou-se um estudo anatômico comparativo do músculo reto femoral entre primatas que possuem posição bípede, os humanos; e quadrúpede, macaco prego Cebus apella e macaco bugio Alouatta guariba, todos fixados em formol $10 \%$ e cuidadosamente dissecados. Nos humanos, o músculo reto femoral apresentou um tendão na espinha ilíaca ântero-inferior (cabeça reta) e outro que acompanha a borda do acetábulo, aderindo firmemente à cápsula articular (cabeça reflexa). Todos os espécimes de macacos apresentaram dois tendões de fixação, apenas com origens e estruturas diferentes. Em 33\% das peças humanas ocorreu um tendão recorrente, tendo uma parte que se une à inserção do músculo glúteo mínimo e outra que se une ao ligamento íliofemoral na linha do trocânter maior. Não foi encontrado em nenhum dos 
espécimes o tendão recorrente. A cabeça reflexa é relativamente fixa e o tendão recorrente tem função de provocar maior estabilidade na parte anterior da articulação do quadril. Pela disposição, comprimento, largura e relação íntima com a cápsula articular, pode-se considerar que há níveis distintos de importância entre as fixações do músculo reto femoral.

Palavras-chave: músculos, primatas, tendão.

\title{
Anatomy of the rectus femoris muscle origin in humans, Cebus apella e Alouatta guariba
}

\begin{abstract}
It was realized a anatomic comparative study of rectus femoris muscle between primates that use the biped position, the humans; the quadrupeds, Cebus apella capuchin and the Alouatta guariba howler monkey, all fixed in formaldehyde $10 \%$ and carefully dissected. In the humans, the rectus femoris muscle showed one tendon on the anterior inferior spine of the ilium (straight head) and another that surround the superior acetabular ridge of the acetabulum (reflected head). All the specimens showed two tendons of fixation to the rectus femoris muscle, only with origin and structures different. In $33 \%$ of the human sides, a recurrent tendon were observed, the presence of one part that joined by the insertion of gluteus minimus muscle and another that joined by the iliofemoral ligament in the greater trochanter. The recurrent tendon wasn't found in any specimens. The reflected head is fixed, and the recurrent tendon has the function of make an additional stability to the anterior part of the hip joint. Because of arrangement, length, width and the close relation with the joint capsule can consider that there are distinct levels of importance among fixations of rectus femoris muscle.
\end{abstract}

Keywords: muscles, primates, tendon.

\section{INTRODUÇÃO}

Os estudos de Anatomia Comparativa de primatas, principalmente daqueles que podem e são utilizados em laboratórios de pesquisa, quer seja de 
AMADO, L.T.M. et al. Anatomia da fixação proximal do músculo reto femoral em humanos, Cebus apella e Alouatta guariba. PUBVET, Londrina, V. 5, N. 12, Ed. 159, Art. 1077, 2011.

ordem clínica ou anatomo-cirurgica, tem sido um tema relevante para inúmeros trabalhos científicos que, de alguma forma, procuram estabelecer possíveis correlações filogenéticas entre os primatas não-humanos e os humanos (CARVALHO - BARROS, 2002).

De acordo com Basmajian e De Luca (1985), o movimento intrínseco é o primeiro sinal inerente da vida animal. Por estas e muitas outras razões, os humanos tem mostrado curiosidade permanente sobre os órgãos da locomoção, em seu próprio corpo em aqueles de outras criaturas, incluindo os primatas não humanos. $\mathrm{Na}$ verdade, alguns dos primeiros experimentos científicos preocupam-se em conhecer o músculo e suas funções.

Os primatas não humanos têm se constituído um importante grupo dentre os animais submetidos a estudos diversos, o que é de suma importância até para o entendimento de sua própria evolução, somando-se ao fato de que o conhecimento pormenorizado de sua Anatomia pode representar fator importante para sua preservação e proteção. Nos últimos 30 anos, o estudo desses primatas tem recebido grande atenção, talvez devido à sua semelhança anatômica, fisiológica e etológica com a espécie humana. (AURICCHIO, 1995; CARVALHO - BARROS, 2002; SANTINI, 1983)

O Cebus apella é um primata de tamanho médio (NAPIER e NAPIER, 1967), o músculo quadríceps femoral é composto por quatro partes e o músculo reto femoral não é separado em cabeça reflexa e reta. O Alouatta guariba, o músculo quadríceps femoral é altamente desenvolvido. O músculo reto femoral possui uma cabeça reflexa e uma cabeça reta. (HILL, 1960; SIRENA (1871 apud HILL, 1962)ํ). O músculo reto femoral dos humanos possui a cabeça reta que se insere na espinha ilíaca antero inferior, a cabeça reflexa que se fixa no sulco acima do acetábulo e na cápsula fibrosa articular (WARWICK; WILLIAMS in GRAY, 1995; LATARJET e LIARD, 1993; DÂNGELO e FATTINI, 2007)

\footnotetext{
${ }^{1}$ Sirena, S. G. Sci. nat. econ.. Palermo, p.164-244, 1871.
} 
O interesse deste trabalho foi realizar um estudo anatômico comparativo do músculo reto femoral, descrevendo sua morfologia topográfica, disposição de fibras musculares, e fixação dos tendões, entre primatas que possuem posição bípede, o Homo sapiens; e quadrúpede, macaco prego Cebus apella e macaco bugio Alouatta guariba.

\section{MATERIAL E MÉTODOS}

Para o desenvolvimento deste trabalho foram utilizados seis membros de macaco bugio (Alouatta guariba), que foram encontrados mortos na rodovia BR 365, de onde foram recolhidos e encaminhados ao IBAMA e posteriormente cedidos aos Laboratórios de Anatomia da Universidade Federal de Uberlândia, Centro Universitário de Patos de Minas e Universidade Federal de Goiás Campus Catalão, para preparação e estudo.

Para comparação com os animais citados anteriormente foram utilizados dez (10) membros inferiores de cadáveres humanos adultos e vinte (20) membros de macaco-prego (Cebus apella). Todo material humano de estudo pertence ao acervo didático do Laboratório de Anatomia Humana do Instituto de Ciências Biomédicas da Universidade Federal de Uberlândia. Os espécimes foram preparados por meio de fixação em formol a $10 \%$, cuidadosamente dissecados com o objetivo de expor o músculo quadríceps femoral em toda extensão e tornar as estruturas anatômicas da articulação do quadril visíveis, principalmente o tendão de fixação proximal do músculo reto femoral.

A preparação das peças anatômicas a serem analisadas foi feita conforme protocolo a seguir:

1- Fixação dos espécimes por perfusão de solução aquosa de formol a 10\%, através da artéria femoral.

2- Conservação dos espécimes imersos em solução de formol a $10 \%$.

3- Dissecação da região de interesse, segundo técnicas usuais.

4- Observações, análise e foto-documentação dos achados anatômicos. 


\section{RESULTADOS}

A anatomia comparativa é uma ciência essencialmente visual e táctil, portanto as observações e descrições feitas durante o processo de dissecação foram importantes para a análise dos resultados. A análise e comparação das estruturas anatômicas de interesse foram realizadas, levando-se em consideração não apenas o local de fixação dos tendões, mas também os aspectos relativos à adaptação de cada espécie no que se refere aos hábitos e costumes.

Em virtude da escassez de dados literários sobre a fixação proximal do músculo reto femoral em macacos, na descrição dos resultados, foi feita uma analogia com a literatura humana, em termos de terminologia. De acordo com a anatomia humana, o músculo reto femoral possui duas cabeças de origem, sendo que a cabeça reta se fixa na espinha ilíaca antero - inferior e a cabeça reflexa fixa-se em um sulco acima do acetábulo e na cápsula fibrosa da articulação do quadril. Ambos os tendões se unem em ângulo agudo com a aponeurose sobre as faces anterior e posterior do músculo reto femoral (BASMAJIAN e De LUCA,1985; LATARJET e LIARD,1993; TUBBS et al., 2006).

Durante as dissecações foi observada uma quantidade considerável de tecido adiposo entre as estruturas anatômicas que compõem o músculo esquelético (BENJAMIN et al., 2008) do humano, do Cebus e do Alouatta. Esse tecido foi encontrado entre os tendões dos músculos reto femoral, sartório e iliopsoas, imerso no tecido conjuntivo que recobre a parte inicial do músculo reto femoral, tanto em sua face anterior quanto na face posterior, entre os músculos e a pele.

Encontrou-se em todas as peças de cadáveres humanos, ao contrário do observado nos primatas Cebus apella e Alouatta guariba, a presença de uma alça na parte mais espessa da cápsula articular (Figura 1), tendo início na face glútea do osso ilíaco, posterior e lateralmente à cabeça reta do músculo reto femoral, superior ao início da fixação da cabeça reflexa no sulco do acetábulo, seguindo até a fossa trocantérica, penetrando sob a inserção do músculo 
glúteo mínimo (WARWICK; WILLIAMS in GRAY, 2005). Esta alça possui íntima relação com o início do tendão recorrente.

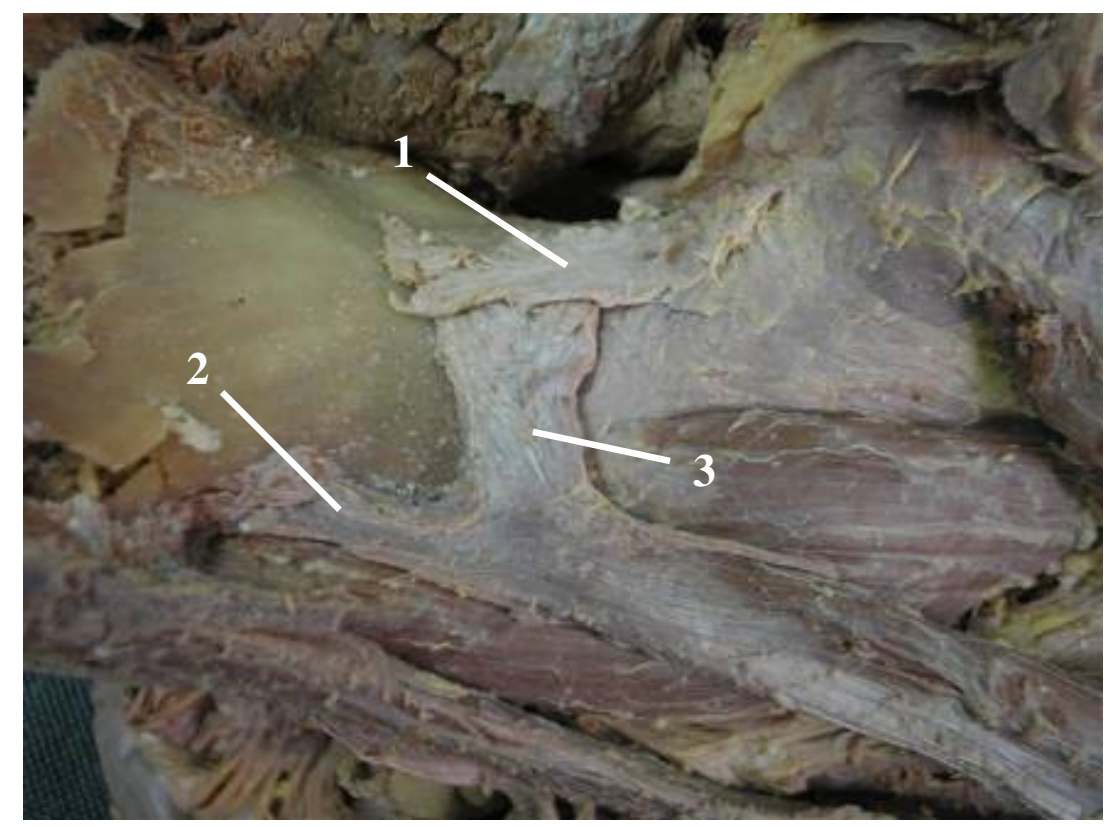

Figura 1: Alça de tecido capsular (1), Cabeça reta do músculo reto femoral (2), Cabeça reflexa do músculo reto femoral (3) de humanos.

Das vinte peças humanas dissecadas, todas apresentaram dois tendões de origem proximal para o músculo reto femoral, um na espinha ilíaca ânteroinferior, denominado cabeça reta e outro que acompanha a borda do acetábulo, aderindo-se firmemente à cápsula articular da articulação do quadril, denominado de cabeça reflexa (DÂNGELO e FATTINI, 2007; LATARJET e LIARD, 1993; WARWICK; WILLIAMS in GRAY, 2005). Em apenas seis das vinte peças dissecadas foi observado mais um tendão, denominado tendão recorrente do músculo reto femoral. Este tendão apresenta uma parte superficial que se une à inserção do músculo glúteo mínimo, localizada no trocânter maior do fêmur e uma porção profunda que se une com o ligamento ílio-femoral na linha do trocânter maior (Figuras 2 e 3) (TUBBS et al., 2006). 


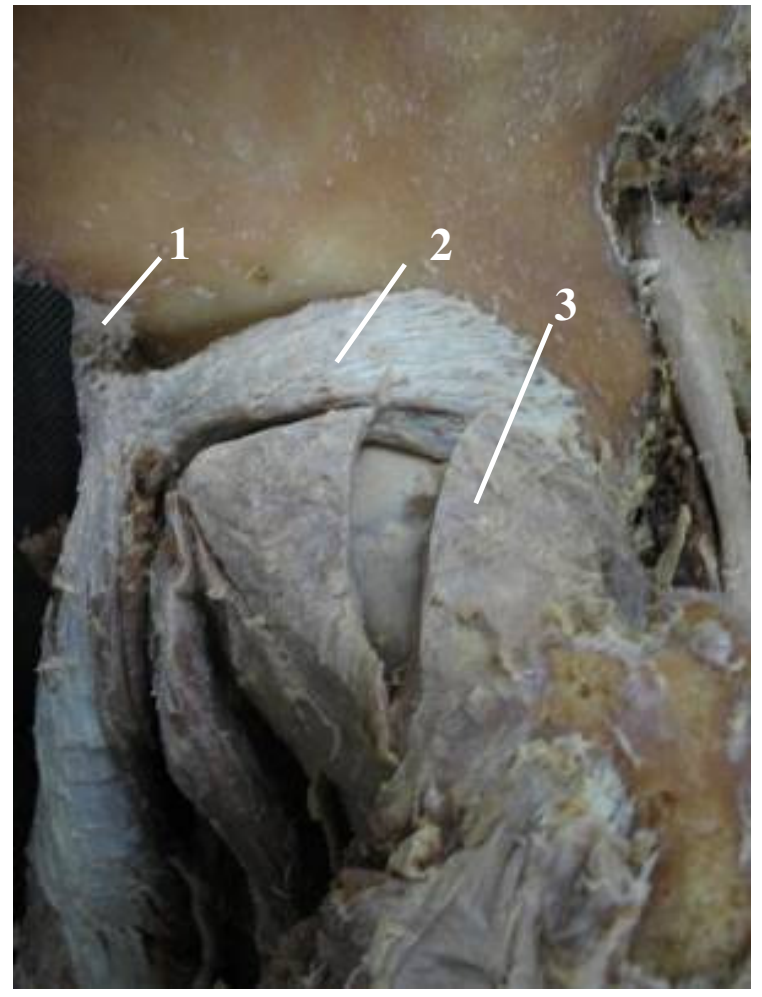

Figura 2: Cabeça reta do músculo reto femoral (1), Cabeça reflexa do músculo reto femoral (2), Cápsula articular da articulação do quadril aberta (3) de humanos

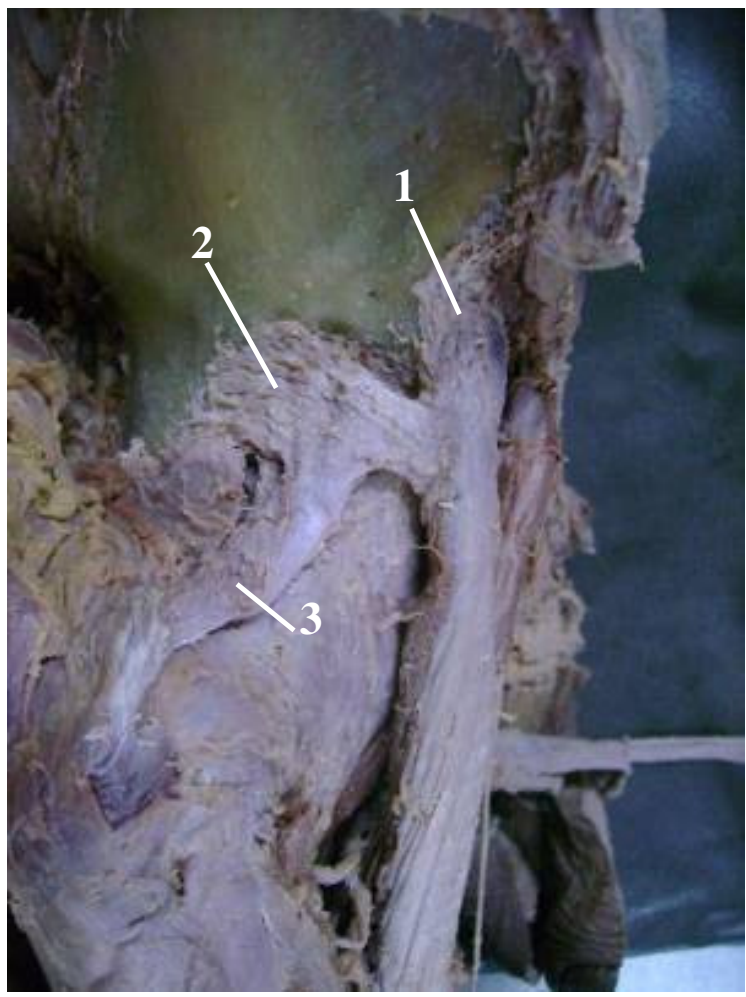

Figura 3: Cabeça reta do músculo reto femoral (1), Cabeça reflexa do músculo reto femoral (2). Tendão recorrente do músculo reto femoral (3) de humanos

Nos cinco espécimes de macaco Cebus apella dissecados (dez membros inferiores), e nos três espécimes de macaco Alouatta guariba dissecados (seis membros inferiores), todos apresentaram dois tendões de origem proximal para o músculo reto femoral, um muito resistente que percorre a margem ventral do ílio, lateralmente ao músculo ílio-psoas e posterior ao $\mathrm{m}$. sartório, denominado cabeça reta, e outro tendão delgado no Cebus, longo e forte no Alouatta, aderindo firmemente à cápsula articular da articulação do quadril, denominado cabeça reflexa (Figuras 4, 5 e 6) (HILL, 1960; SIRENA (1871 apud 
AMADO, L.T.M. et al. Anatomia da fixação proximal do músculo reto femoral em humanos, Cebus apella e Alouatta guariba. PUBVET, Londrina, V. 5, N. 12, Ed. 159, Art. 1077, 2011.

HILL, $\left.1962^{1}\right)$ ). No Alouatta guariba, os tendões de origem proximal se unem em um ângulo agudo de $45^{\circ}$ e se espalham como uma aponeurose sobre todo o ventre muscular. Nenhum dos espécimes estudados apresentaram o tendão recorrente do músculo reto femoral.

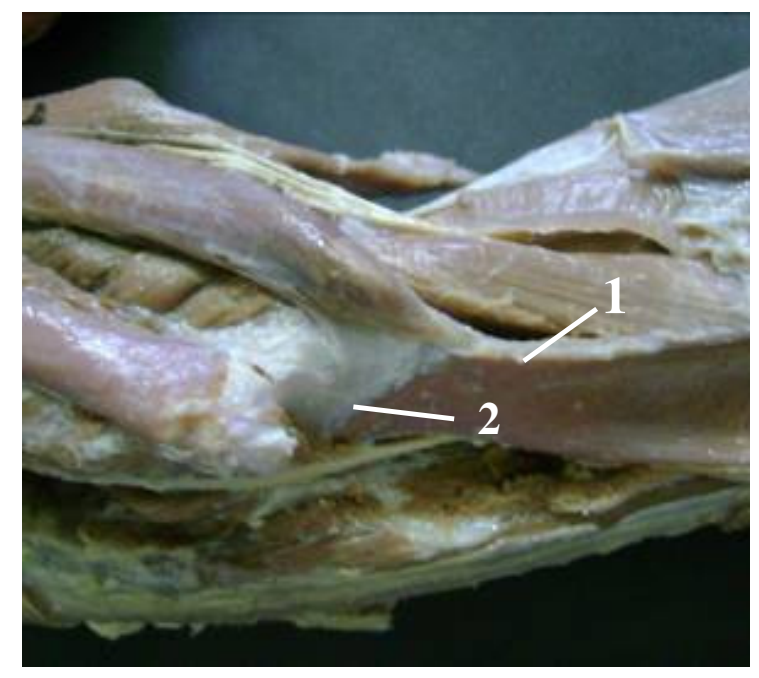

Figura 4: Cabeça reta do músculo reto femoral (1), Cabeça reflexa do músculo reto femoral (2) do Cebus apella.

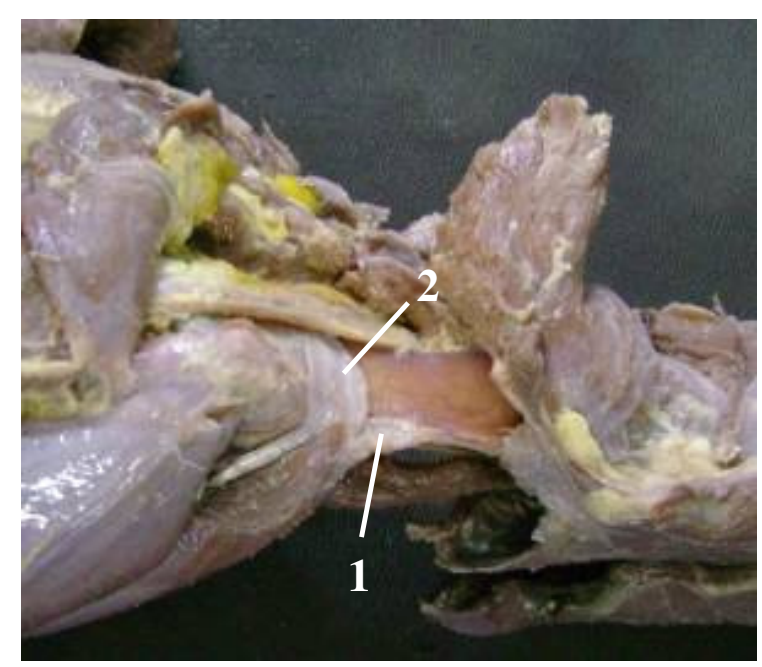

Figura 5: Cabeça reta do músculo reto femoral (1), Cabeça reflexa do músculo reto femoral (2) do Cebus apella.

\footnotetext{
${ }^{1}$ Sirena, S. G. Sci. nat. econ.. Palermo, p.164-244, 1871.
} 


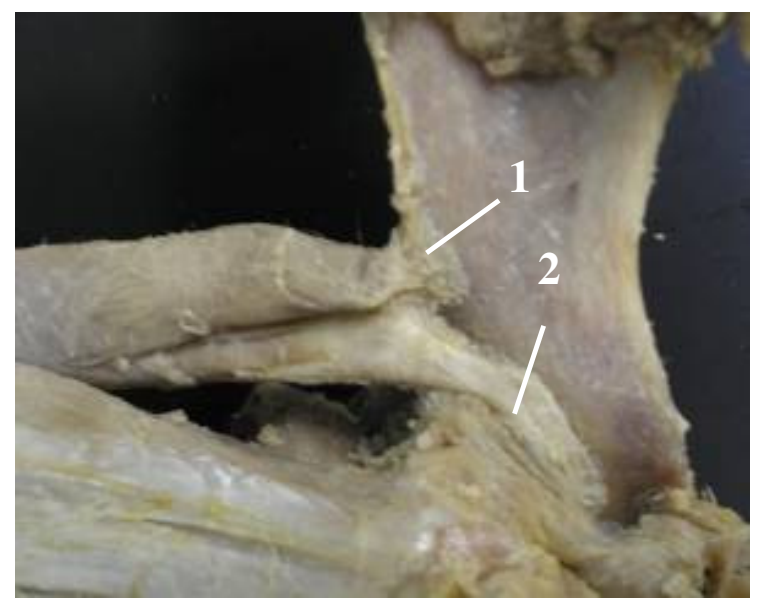

Figura 6: Cabeça reta do músculo reto femoral (1), Cabeça reflexa do músculo reto femoral (2) do Alouatta guariba.

\section{DISCUSSÃO}

Nesta pesquisa realizou-se um estudo comparativo da anatomia da fixação proximal do músculo reto femoral de primatas que possuem deslocamento de forma bípede, os humanos, e quadrúpede, os macacos prego e bugio.

Nesta pesquisa observou-se que nos humanos, no Cebus apella, e no Alouatta guariba o músculo quadríceps femoral nos humanos está constituído por quatro músculos, separados em sua origem, mas com inserção única na patela e na tíbia. O músculo reto femoral é o único músculo do quadríceps femoral que cruza por toda a coxa iniciando-se no quadril e estendendo-se até o joelho (GARDNER, GRAY e O'RAHILLY, 1988; TESTUT e LATARJET, 1979).

Sirena (1871 apud Hill, 1962) ${ }^{3}$ ao descrever a musculatura do Alouatta guariba, relata que o quadríceps femoral é muito desenvolvido e que os músculos vasto medial e vasto lateral são os mais volumosos, constatou-se

\footnotetext{
${ }^{3}$ Sirena, S. G. Sci. nat. econ.. Palermo, p.164-244, 1871.
} 
que em Cebus apella e no Alouatta guariba, as quatro partes do músculo quadríceps femoral são perfeitamente identificáveis, sendo, porém, o músculo vasto lateral o mais desenvolvido entre eles.

No Cebus apella e no Alouatta guariba, o músculo reto femoral apresenta igualmente, forma fusiforme, mas não se identificaram fibras com disposição bipenada, o que contradiz com Palastanga, Field e Soames (2000) e Warwick; Williams in Gray (1995), dizem que, as fibras superficiais e profundas apresentam disposições paralelas, levemente convergentes distalmente. A aponeurose envolve toda a metade distal, medial e lateral do músculo. $\mathrm{Na}$ superfície profunda da extremidade proximal do músculo, a aponeurose se prolonga até formar os tendões, concordando com as descrições nos humanos.

Nesta pesquisa, constata-se que todas as peças humanas e dos macacos, apresentaram dois tendões de origem, a cabeça reta e reflexa, sendo que nos humanos, a cabeça reta está firmemente fixada à espinha ilíaca antero-inferior e a cabeça reflexa fixada próximo à borda acetabular, aderindo-se firmemente à cápsula da articulação do quadril (Figura 2 e 3 ) e funcionando como estrutura anatômica importante durante os movimentos articulares contribuindo para a manutenção da cabeça do fêmur na fossa do acetábulo (BENJAMIN, KAISER e MILZ, 2008; DANGELO e FATTINI, 2007; HASSELMAN et al, 1995; VARISE et al., 2009; WARWICK; WILLIAMS in GRAY, 2005).

As observações do macaco Cebus apella contradizem as descrições de Hill (1960) ao afirmar que o músculo reto femoral não é separado em cabeça reflexa e reta no gênero Cebus. O músculo reto femoral no Cebus apresenta um tendão delgado aderindo firmemente à cápsula articular da articulação do quadril (Figura 4 e 5). E já no Alouatta guariba, nossas observações corroboram com as descrições de Hill (1960) e de Sirena (1871 apud Hill, $1962)^{4}$, pois encontramos um tendão longo e forte que se adere firmemente à cápsula articular da articulação do quadril (Figura 6).

\footnotetext{
${ }^{4}$ Sirena, S. G. Sci. nat. econ.. Palermo, p.164-244, 1871.
} 
Constatou-se que o tendão da cabeça reflexa é relativamente fixo, e o tendão recorrente pode ter a função de simplesmente produzir uma estabilidade adicional para a parte anterior da articulação do quadril. O músculo reto femoral encontra-se quase totalmente envolvido por aponeurose, o que a torna mais forte, protege melhor a articulação e a torna mais resistente. Pelas características anatômicas da cabeça reflexa, é possível inferir que, para os humanos e para o Alouatta guariba, esta possa ser considerada a parte principal e a cabeça reta como acessória. O que vem de encontro com Roger Willians (1873 apud Testut e Latarjet, 1979) ${ }^{5}$. Já no Cebus apella, o tendão reto pode ser considerado a inserção principal, pois é mais robusto e melhor posicionado em relação à direção das fibras musculares quando comparado ao tendão da cabeça reflexa.

Na pesquisa observou-se que em $33 \%$ das peças humanas foi constatado um terceiro tendão, o tendão recorrente, a qual exibe duas partes, uma superficial que se une ao músculo glúteo mínimo para inserir no trocânter maior do fêmur e uma porção profunda que se junta ao ligamento ílio-femoral, na linha do trocânter maior (Figura 3), conforme Paturet (1951 apud Tubbs et al.,2006) ${ }^{6}$; Tubbs et al. (2006). No Cebus apella e no Alouatta guariba foram observadas a cabeça reta e reflexa, mas não tendão recorrente.

Uma análise comparativa dos ângulos entre os tendões da cabeça reflexa e reta e entre os tendões da cabeça reflexa e o tendão recorrente, quando presente, foi realizada. A partir de medições, observou-se que o ângulo entre o tendão da cabeça reflexa e o tendão recorrente nos humanos foi de $60^{\circ} \mathrm{em}$ todas as peças com este tendão (BASMAJIAN e DE LUCA, 1985; LATARJET e LIARD, 1993; TUBBS et al., 2006). Não foi medido o ângulo entre a cabeça reflexa e o tendão recorrente no Cebus apella e no Alouatta guariba porque não possuem o tendão recorrente. Os ângulos apresentados entre o tendão da cabeça reta e da cabeça reflexa foram diferentes entre as espécies estudadas,

\footnotetext{
${ }^{5}$ Roger Willians, Journal of Anatomy and Physiology, 1873.

${ }^{6}$ Paturet G. Traité d' Anatomie Humaine. v. 2. Masson et Cie: Paris, p. 599, 1951
} 
AMADO, L.T.M. et al. Anatomia da fixação proximal do músculo reto femoral em humanos, Cebus apella e Alouatta guariba. PUBVET, Londrina, V. 5, N. 12, Ed. 159, Art. 1077, 2011.

a disposições dos tendões de origem do músculo reto femoral são muito distintas das disposições apresentadas pelos humanos, pelo macaco prego Cebus apella, e pelo macaco bugio Alouatta guariba.

\section{CONCLUSÃO}

Pode-se concluir que nos primatas bípedes, os humanos, a fixação proximal do músculo reto femoral tem a função de estabilização da articulação do quadril e sustentação corporal, e nos primatas não humanos, Cebus apella e Alouatta guariba, função de aumentar a força do movimento.

\section{REFERÊNCIAS}

AURICCHIO, P. Primatas do Brasil. São Paulo: Terra Brasilis, 1995.

BASMAJIAN, J. V.; DE LUCA, C. J. Muscle alive: their function revealed by electromyography. 5. ed. Baltimore: Williams \& Wilkins, 1985.

BENJAMIN, M.; KAISER, E.; MILZ, S. Structure-function relationships in tendon: a review. Journal of Anatomy, London, v.212, n.3 p.211-228, 2008.

CARVALHO-BARROS, R. A. Estudo anatômico dos plexos lombar, sacral e coccígeo do macaco Cebus apella: origem, composição e nervos resultantes. São Paulo: USP, 2002. 146f. Dissertação (Mestrado em Anatomia dos Animais Domésticos) - Programa de Pós-graduação em Anatomia dos Animais Domésticos, Faculdade de Medicina Veterinária e Zootecnia, Universidade de São Paulo, São Paulo, 2002.

DANGELO, J. G.; FATTINI, C. A. Anatomia humana: sistemática segmentar. Rio de Janeiro: Atheneu, 2007.

GARDNER, E.; GRAY, D. J.; O'RAHILLY, R. Anatomia. 4. ed. Rio de Janeiro: Guanabara Koogan, 1988.

HASSELMAN, C. T.; BEST, T. M.; HUGHES, C.; MARTINEZ, S.; GARRETT, W. E.; An explanation for various rectus femoris strin injuries using previously undescribed muscle architecture. The American Journal of Sports Medicine, Chicago, v. 23, n.4, p. 493-499, Jul. 1995.

HILL, W. C. O. Primates : comparative anatomy and taxonomy. Edinburgh: R \& R Clark, 1960.

LATARJET, M.; LIARD, R. A. Anatomia humana. São Paulo: Médica Panamericana, 1993

NAPIER, J.P.; NAPIER, P.H. Evolutionary aspects of primate locomotion. American Journal of physical anthropology, Hoboken, v.27, n.3, p.333-341, 1967.

PALASTANGA, N.; FIELD, D.; SOAMES, R. Anatomia e movimento humano: estrutura e função. 3 ed. São Paulo: Manole, 2000. 
AMADO, L.T.M. et al. Anatomia da fixação proximal do músculo reto femoral em humanos, Cebus apella e Alouatta guariba. PUBVET, Londrina, V. 5, N. 12, Ed. 159, Art. 1077, 2011.

SANTINI, M. E. L. Alimentação e padrões de atividade de Alouatta caraya (Primates, Cebidae), reintroduzidos no Parque Nacional de Brasília, Brasília: UnB, 1985. 133p. Dissertação (Mestrado em Ecologia) - Programa de Pós-graduação em Ecologia, Instituto de Ciências Biológicas, Universidade de Brasília, Brasília, 1985.

TESTUT, L.; LATARJET, A. Anatomia humana. Barcelona: Salvat Editores, 1979.

TUBBS, R.S.; SALTER, G.; OAKES, W.J.; STETLER, W.JR.; SAVAGE, A.J.; SHOJA, M.M.; SHAKERI, A.B.; LOUKAS, M. Does a third head of the rectus femoris muscle exist?. Via Médica, Gdansk, v.65, n.3, p.377-380, 2006.

VARISE, E. M; FONTES, S. V.; FUKUJIMA, M. M.; PRADO, G. F. Revisão dos conceitos sobre a evolução bípede e aplicação na Fisioterapia. Revista Neurociências, São Paulo v. 17, n.3, p. 246-254, Mar. 2009.

WILLIANS, P. L.; WARWICK, R.; DYSON, M.; BANNISTER, L. H. Gray anatomia. 37. ed. Rio de Janeiro: Guanabara Köogan, 1995. v.1. 